\title{
AKTIVITAS EKSTRAK TEMU KUNCI (Boersenbergia pandurata Roxb. Schlecht.) TERHADAP JAMUR PENYEBAB PITIRIASIS VERSIKOLOR (Malassezia sp. Malassezia globosa \& Malassezia furfur).
}

\author{
Wahyu Widayat, Nisa Naspiah, Arsyik Ibrahim \\ Laboratorium Biologi Farmasi, Fakultas Farmasi Universitas Mulawarman Samarinda \\ Kalimantan Timur- Indonesia. \\ E-mail : boersenbergiapandurata@gmail.com
}

\begin{abstract}
Abstrak
Malassezia merupakan jamur dimorfik lipofilik salah satu penyebab penyakit Pitiriasis Versikolor. Boesenbergia pandurata Roxb. Schlecht. merupakan salah satu suku jahejahean (Zingiberaceae) yang ditemukan di Asia Tenggara. Di Indonesia, tanaman ini dikenal sebagai "temu kunci". Secara etnobotani tanaman ini telah banyak dimanfaatkan, salah satunya sebagai pengobatan terhadap infeksi. Tujuan penelitian ini adalah mengetahui nilai KHM dan KBM ekstrak etanol temu kunci, serta golongan senyawa yang memberikan aktivitas antijamur terhadap Malassezia sp., yaitu Malassezia globosa dan Malassezia furfur. Metode yang digunakan dalam penelitian ini adalah metode difusi agar (Disk diffusion), dilusi cair (Broth Dilution), dan KLT Bioautografi. Hasil penelitian menunjukan bahwa ekstrak etanol B. pandurata memiliki nilai KHM pada konsentrasi $1 \%$ dan KBM pada konsentrasi 10\%. Profil kromatogram menunjukan spot senyawa yang memberikan aktivitas, masing-masing berada pada rf 0.11-0.64, yang ditandai dengan zona bening pada rf tersebut. Senyawa kimia yang memberikan aktivitas tersebut merupakan golongan senyawa flavonoid, kalkon dan turunannya. Berdasarkan hasil penelitian diketahui bahwa $B$. pandurata sangat berpotensi sebagai antijamur penyebab Pitiriasis Versikolor.
\end{abstract}

Keyword : Boersenbergia pandurata Roxb. Schlecht., Antijamur, Temu kunci, Malassezia.

\begin{abstract}
Malassezia is a lipophilic Dimorphic fungus, one of the causes of disease Pityriasis versicolor. Boesenbergia pandurata Roxb. Schlecht. is one of the tribes of ginger (Zingiberaceae) that found in Southeast Asia. In Indonesia, the plant is known as a "Temu Kunci". In ethnobotany of this plant has been used, one of them as a treatment for infections. The purpose of this study was to determine the value of MIC and MBC Temu kunci ethanol extract, as well as classes of compounds that provide the antifungal activity against Malassezia sp., that Malassezia globosa and Malassezia furfur. The method used in this research is the agar diffusion method (Disk diffusion), the dilution liquid (broth dilution), and Bioautografi TLC. The test results showed that the ethanol extract of $B$. pandurata have MIC at a concentration of $1 \%$ and MBC at a concentration of $10 \%$. Chromatogram profile shows spot that provide activities, each of which is in Rf 0.11-0.64, which is marked by a clear zone at the Rf. Chemical compounds that give these activities were class of flavonoids, kalkon and derivatives. Based on the results revealed that $B$. pandurata great potential as an antifungal cause of Pityriasis versicolor.
\end{abstract}

Keyword : Boersenbergia pandurata Roxb. Schlecht., Antijamur, Temu kunci, Malassezia. 


\section{Pendahuluan}

Penyakit kulit masih sering dijumpai di berbagai daerah tropis. Indonesia merupakan negara beriklim tropis dan lembab, sehingga penyakit ini masih banyak menginfeksi masyarakat di berbagai daerah di Indonesia, khususnya di Kalimantan Timur. Salah satu penyakit kulit yang sering ditemui adalah penyakit Pitiriasis versikolor (PV) atau panu. Penyakit ini merupakan penyakit yang disebabkan karena infeksi jamur nondermatofitosis mikosis superfisialis (Budimulja, 2007), yang ditandai dengan perubahan pigmen kulit yang disebabkan oleh kolonisasi jamur lipofilik dimorfik dari flora normal kulit pada stratum korneum (Moniri, et al., 2009). Spesies Malassezia merupakan jamur dimorfik lipofilik yang tergolong flora normal yang dapat menyebabkan terjadinya Pitiriasis versikolor. Jamur ini dapat diisolasi dari kerokan kulit yang berasal dari hampir seluruh area tubuh terutama di area yang kaya kelenjar sebasea, seperti dada, punggung, dan area kepala (Pfaller, et al., 2009).

Guna mengatasi kondisi infeksi jamur tersebut, masyarakat Kalimantan Timur menggunakan beberapa tanaman obat. Salah satunya adalah tanaman temu kunci (Boesenbergia pandurata Roxb. Schlecht.). Tanaman ini merupakan salah satu suku jahejahean (Zingiberaceae) yang ditemukan di Asia Tenggara. Tanaman ini tumbuh liar di hutan jati. Rimpang B. pandurata digunakan sebagai obat tradisional untuk pengobatan peradangan pada rahim wanita dan untuk pengobatan infeksi vagina (Heyne, 1987). Rimpang dari tanaman ini adalah salah satu komponen jamu "jamu" di Indonesia (Eisai, 1995). Dalam referensi dari obat herbal yang diterbitkan Badan Pengawas Obat dan Makanan (Badan POM atau BPOM Republik Indonesia), rimpang B. pandurata digunakan sebagai anti-inflamasi (BPOM RI, 2007) dan anti-kanker (BPOM RI, 2011).

Berdasarkan hasil penelitian terdahulu, kandungan utama $B$. pandurata adalah minyak atsiri dan juga beberapa senyawa golongan flavonoid. Sebagian besar flavonoid memiliki kerangka struktur yang sederhana (pinostrobin dan pinoscembrin), beberapa subtituen (gugus prenyl) dalam struktur utamanya (Tuchinda, et al., 2002; Win, et al., 2008) dan beberapa turunan kalkon (panduratin). Senyawa tersebut menunjukkan berbagai aktivitas biologis, seperti antikanker (Kirana, et al., 2007), antiinflamasi (Tewtrakul, et al., 2009), dan antimikroba (Rukayadi, et al., 2009; Yanti, et al., 2009; Rukayadi, et al., 2010).

Berdasarkan hasil pengkajian baik secara empiris maupun in-vitro menunjukkan bahwa tanaman daerah tropis ini $B$. pandurata mempunyai potensi yang cukup potensial untuk dikembangkan sebagai bahan obat dan sediaan farmasi. Penelitian ini bertujuan untuk mengetahui aktivitas eksrak temu kunci terhadap jamur penyebab pitiriasis vesikolor (penyakit panu), serta golongan senyawa yang memberikan aktivitas tersebut.

\section{Metodologi penelitian}

Alat

Cawan petri $\left(\right.$ Normax $\left.^{\circledR}\right)$, tabung reaksi $\left(\right.$ Pyrex $\left.^{\circledR}\right)$, ose (loop), Mikropipet (Dragan LAB ${ }^{\circledR}$ ), Autoclave (Tomy SX $700^{\circledR}$ ), LAF, Alat gelas yang lazim digunakan.

\section{Bahan}

Isolat Malassezia furfur, Malassezia sp., dan Malassezia globosa, SDA (Sabouraund dextrose agar Merk®), DMSO, Tween, Extraktor Chamber, Rotary EvaPrator $\left(\mathrm{BUCHI}^{\circledR}\right)$, Plat KLT silica $\mathrm{F}^{254}$ (Merk $\left.^{\circledR}\right)$, Silica g $60 \mathrm{H}\left(\right.$ Merk $\left.^{\circledR}\right)$. 


\section{Preparasi dan Pembuatan Ektrak}

Rimpang B. pandurata diperoleh dari Kutai Kartanegara Kalimantan Timur. Ekstrak temu kunci diperoleh melalui proses sortasi, pencucian, pengeringan, penghalusan, dan ekstraksi secara maserasi. Sebanyak $1 \mathrm{~kg}$ simplisia diekstrasi mengunakan etanol $96 \%$ ( \pm 2 Liter) dan diremaserasi sebanyak 3 kali. Kemudian dipekatkan mengunakan rotary evaporator, lalu dikering anginkan pada suhu ruang.

\section{Aktivitas Antimikroba}

\section{Difusi Agar (Disk Diffusion)}

Ekstrak etanol B. Pandurata yang telah kering dibuat konsentrasi $10 \%$ dengan menambahkan $10 \%$ DMSO dan $10 \%$ Twen 80 dalam $10 \mathrm{~mL}$ sebagai larutan stok. Kemudian dibuat seri konsentrasi (8,5,3 dan 1) \% dengan volume akhir $5 \mathrm{~mL}$. Sebanyak 10 mL medium SDA dimasukkan ke dalam cawan petri yang berisikan $100 \mu \mathrm{L}$ suspensi jamur Malassezia furfur. Sebanyak $20 \mu \mathrm{L}$ larutan uji diteteskan pada paper disc, setelah meresap dengan baik, paper disc diletakkan di atas permukaan medium yang telah memadat, lalu diinkubasi pada suhu $28^{\circ} \mathrm{C}$ selama $2 \times 24$ jam. Diamati dan diukur zona bening yang terbentuk.

\section{Dilusi Cair (Broth Dilusion)}

Pengujian ini dilakukan mengunakan medium cair SDB. Ke dalam tabung reaksi masing-masing diisi larutan uji dengan konsentrasi (10,8,5,3 dan 1) \%, medium, serta supensi jamur dengan volume akhir $5 \mathrm{~mL}$. Inkubasi pada suhu $25-28^{\circ} \mathrm{C}$ selama 2 x 24 jam. Nilai KHM dan KBM ditunjukan pada tabung yang tidak terdapat pertumbuhan jamur. Kemudian dilakukan konfirmasi dengan cara menginokulasikan hasil tersebut pada media SDA padat. Hasil positif ditandai dengan tidak adanya pertumbuhan pada permukaan media.

\section{Aktivitas Metabolit Skunder (KLT Bioautografi)}

Sebanyak $15 \mathrm{~mL}$ medium yang telah dicampur dengan suspensi jamur $(100 \mu \mathrm{L})$ dimasukan ke dalam cawan petri dan dibiarkan memadat. Disiapkan plat KLT $( \pm 8 \mathrm{~cm})$, lalu ekstrak ditotolkan dengan jarak totolan awal $1 \mathrm{~cm}$ dan akhir $0,5 \mathrm{~cm}$, sehingga jarak pengembangan $6,5 \mathrm{~cm}$. Sebanyak 1 gram sampel (ekstrak etanol) dilarutkan dengan etil asetat secukupnya $( \pm 2 \mathrm{~mL})$, kemudian ditotolkan sebanyak $10 \mu \mathrm{L}$ dan dikembangkan menggunakan pengembang heksan : etil asetat (7: 3). Setelah kering, plat KLT diletakkan di atas permukaan medium dalam cawan petri yang telah bercampur dengan suspensi jamur selama 30-60 menit. Inkubasi pada suhu $25-28^{\circ} \mathrm{C}$ selama 2 x 24 jam. Jarak rf spot yang memberikan aktivitas dihitung, kemudian dilakukan identifikasi golongan senyawa tersebut.

\section{Analisis Hasil}

Aktivitas antimikroba ekstrak ditentukan dengan mengukur diameter zona bening pada uji difusi agar. Sementara itu, hasil uji dilusi cair digunakan untuk menentukan nilai KHM dan KBM ekstrak. Hasil uji yang diperoleh kemudian dianalisis menggunakan ANAVA satu arah dan uji BNJ Duncan.

\section{Hasil Dan Pembahasan}

Tanaman B. Pandurata, yang digunakan untuk penelitian ini dikumpulkan dari daerah Kutai Kartanegara, Kalimantan Timur. Gambar 1 menunjukkan bentuk rimpang tanaman B. Pandurata yang digunakan dalam penelitian ini. 


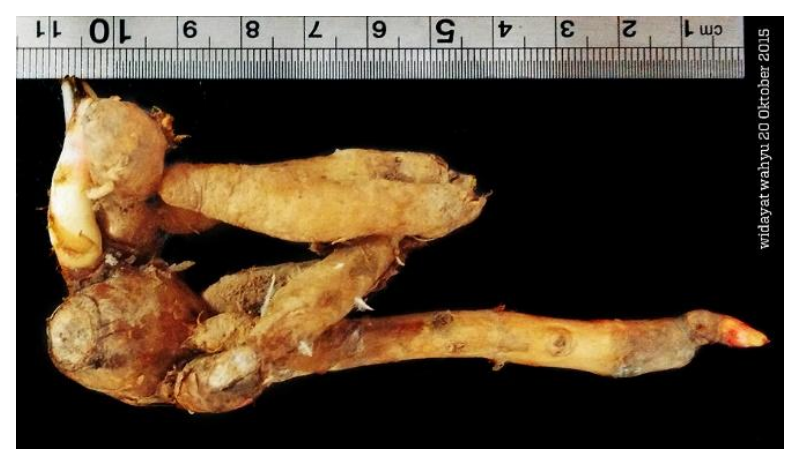

Gambar 1. Rimpang B. Pandurata (Temu Kunci)

Setelah dikumpulkan dan dibuat menjadi simplisia, rimpang B. Pandurata diekstraksi dengan metode maserasi menggunakan pelarut etanol $96 \%$. Remaserasi dilakukan sebanyak 3 kali untuk memaksimalkan kandungan metabolit sekunder yang tertarik ke dalam ekstrak yang dihasilkan. Kemudian dilakukan pengujian antimikroba ekstrak $B$. Pandurata dengan metode difusi agar, dilusi cair, dan KLT bioautografi.

Metode difusi agar merupakan metode yang cepat dan sederhana yang digunakan untuk pengujian antimikroba. Hasil dari pengujian dengan metode ini adalah terbentuknya zona bening disekitar paper disc. Zona bening menunjukkan ekstrak yang diuji memiliki aktivitas antimikroba, yang menyebabkan mikroba uji tidak dapat tumbuh. Semakin besar diameter zona bening yang dihasilkan, maka semakin tinggi aktivitas zat uji tersebut. Pada penelitian ini mikroba uji yang digunakan adalah 3 spesies jamur Malassezia, yaitu, Malassezia Sp., M. furfur, dan M. globosa..

Hasil pengujian dengan metode difusi agar dapat dilihat pada Tabel 1. Berdasarkan perhitungan statistik ANOVA dilanjutkan dengan Uji BNJ Duncan diperoleh hasil bahwa masing-masing konsentrasi memiliki aktivitas terhadap Malasezzia dengan konsentrasi terbaik masing-masing adalah $8 \%$ (terhadap Malassezia Sp.), $10 \%$ (terhadap M. furfur), dan konsentrasi $8 \%$ ((terhadap $M$. globosa).

Tabel. 1 Aktivitas Ekstrak Etanol B. pandurata dengan nilai diameter zona bening

\begin{tabular}{ccccccc}
\hline \multirow{2}{*}{ Jamur } & \multicolumn{6}{c}{ Zona Bening (Konsentrasi \%) } \\
\cline { 2 - 7 } & $\mathbf{1 0}$ & $\mathbf{8}$ & $\mathbf{5}$ & $\mathbf{3}$ & $\mathbf{1}$ & Kontrol \\
\hline $\begin{array}{c}\text { Malassezia } \\
\text { Sp. }\end{array}$ & $8.60 \pm 0.43$ & $9.78 \pm 0.51^{*}$ & $9.65 \pm 0.27$ & $9.24 \pm 0.68$ & $7.01 \pm 0.23$ & - \\
$\begin{array}{c}\text { Malassezia } \\
\quad \text { furfur }\end{array}$ & $10.61 \pm 0.98^{*}$ & $10.38 \pm 0.15$ & $9.95 \pm 0.44$ & $9.80 \pm 0.64$ & $7.08 \pm 0.41$ & - \\
$\begin{array}{c}\text { Malassezia } \\
\text { globosa }\end{array}$ & $10.15 \pm 0.36$ & $11.13 \pm 0.64 *$ & $10.07 \pm 0.36$ & $9.67 \pm 0.48$ & $7.77 \pm 0.37$ & - \\
\hline
\end{tabular}

Ket : *Konsentrasi Terbaik

Metode lainnya yang digunakan adalah dilusi cair (broth dilusion). Pada metode ini, media yang digunakan adalah media cair dan pengujian dilakukan menggunakan tabung reaksi. Pada pengujian ini, aktivitas antimikroba ekstrak dilihat dari tingkat kekeruhan media di dalam tabung reaksi. Semakin keruh media di dalam tabung, maka semakin banyak mikroba yang tumbuh, yang menunjukkan aktivitas pada konsentrasi tersebut rendah, begitu pula sebaliknya. Pengujian dengan metode dilusi cair digunakan 
untuk menentukan Konsentrasi Hambat Minimum (KHM) dan Kadar Bunuh Minimum (KBM) dari ekstrak B. Pandurata secara kualitatif. KHM merupakan konsentrasi terkecil yang masih mampu menghambat pertumbuhan mikroba, sedangkan KBM merupakan konsentrasi terkecil yang mampu menghambat pertumbuhan bakteri (Efendi dan Hertiani, 2013)

Hasil pengujian menggunakan metode dilusi cair dapat dilihat pada Tabel 2 dan Gambar 3. Hasil pengujian tersebut menunjukkan bahwa nilai KHM ekstrak B.pandurata terdapat pada konsentrasi $3 \%$ dan nilai KBM terdapat pada konsentrasi $10 \%$.

Tabel.2 Nilai kadar hambat minimum dan kadar bunuh minimum ekstrak B.pandurata

\begin{tabular}{cccccc}
\hline \multirow{2}{*}{ Kapang } & \multicolumn{7}{c}{ Zona Bening (Konsentrasi \%) } \\
\cline { 2 - 6 } & $\mathbf{1 0}$ & $\mathbf{8}$ & $\mathbf{5}$ & $\mathbf{3}$ & $\mathbf{1}$ \\
\hline Malassezia Sp. & ++ & ++ & ++ & + & + \\
$\begin{array}{c}\text { Malassezia } \\
\text { furfur }\end{array}$ & ++ & ++ & ++ & + & + \\
$\begin{array}{c}\text { Malassezia } \\
\text { globosa }\end{array}$ & ++ & ++ & ++ & + & + \\
\hline
\end{tabular}

Ket : ++ : KBM, + : KHM
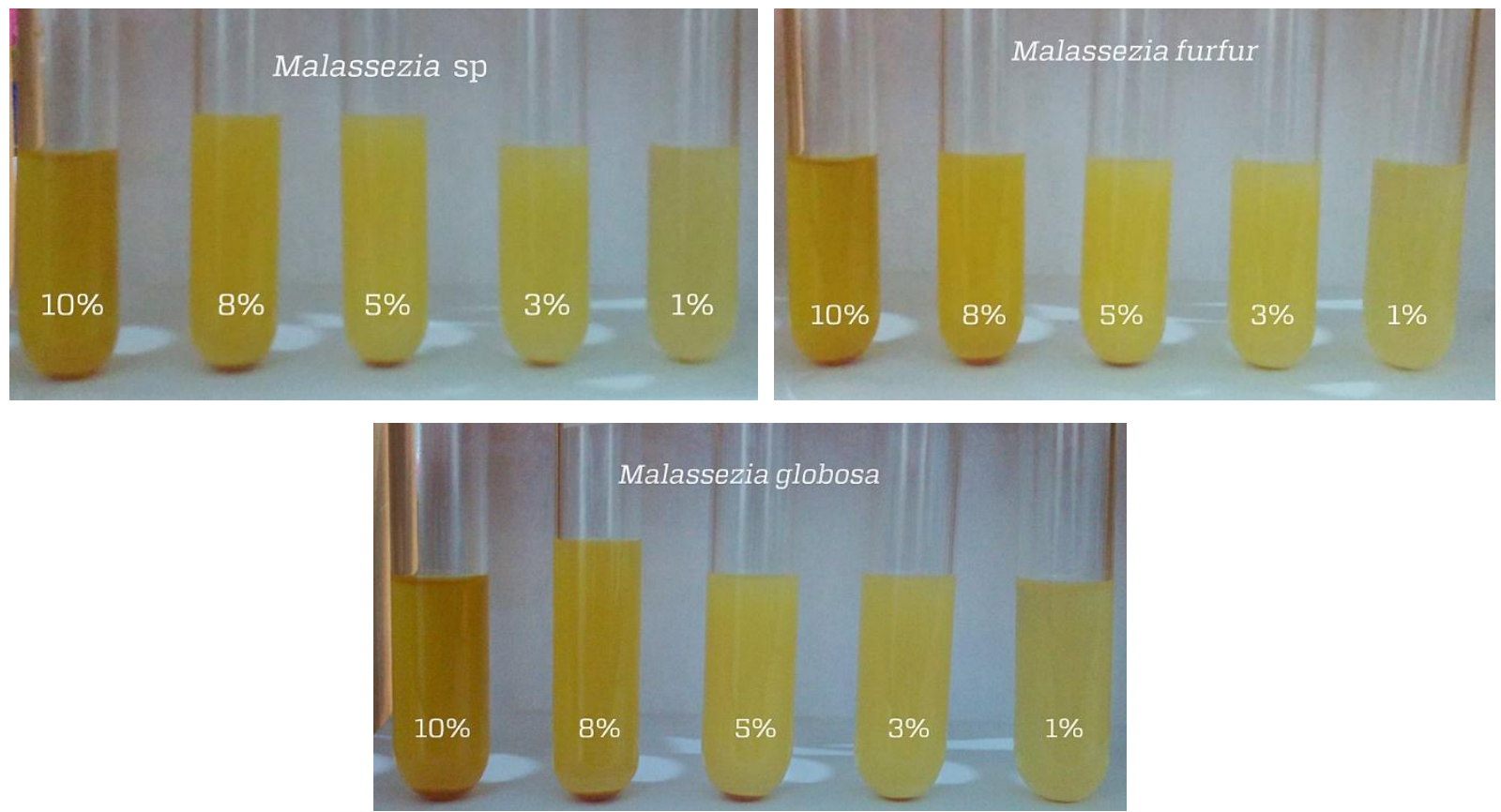

Gambar 3. Dilusi cair ektrak B. pandurata

Setelah menentukan nilai KHM dan KBM ekstrak, maka dilakukan identifikasi golongan metabolit sekunder yang memberikan aktivitas antimikroba, menggunakan metode KLT bioautografi. Hasil KLT bioautografi dapat dilihat pada Gambar 4. Hasil tersebut menunjukkan bahwa metabolit skunder yang terdapat di dalam ekstrak memiliki 
aktivitas terhadap ketiga spesies Malassezia. Aktivitas tersebut ditandai dengan terbentuknya zona bening pada spot yang terpisah sesuai dengan nilai Rf nya.

Untuk mengetahui golongan metabolit sekunder yang memberikan aktivitas tersebut, maka plat KLT diamati di bawah sinar UV $254 \mathrm{~nm}$, UV $366 \mathrm{~nm}$, dan disemprotkan dengan pereaksi spesifik, yaitu $\mathrm{H}_{2} \mathrm{SO}_{4}$, sitroborat, $\mathrm{LB}$, dan $\mathrm{FeCl}_{3}$.

Nilai Rf dari setiap spot pada plat KLT ditentukan. Pada plat tersebut terdapat 11 spot senyawa. Adapun nilai Rf pada hasil kromatogram ektrak $B$. pandurata dengan larutan pengembang heksan : etil asetat (7:3) menunjukkan bahwa terdapat 11 spot senyawa dengan nilai $\operatorname{Rf}$ spot $1=0.07$, spot $2=0.18$, spot $3=0.26$, spot $4=0.43$, spot $5=$ 0.49 , spot $6=0.53$, spot $7=0.61$, spot $8=0.64$, spot $9=0.69,10=0.76,11=0.8$.

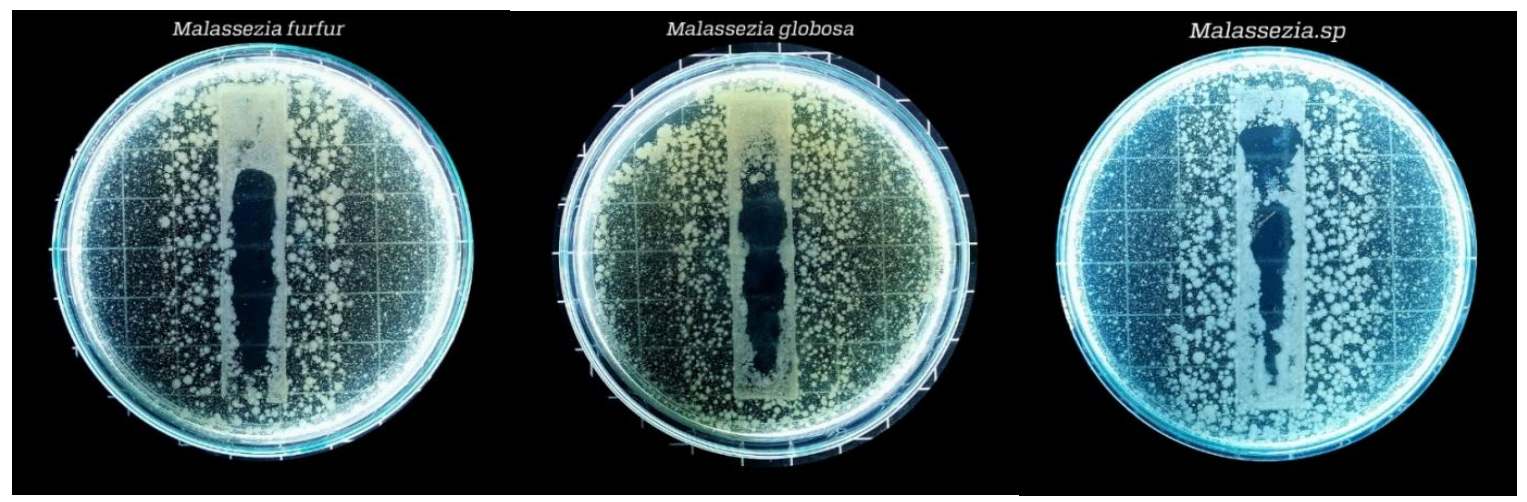

Gambar 4. KLT Bioautografi Ekstrak B. pandurata.

Hasil pengamatan plat KLT dapat dilihat pada Gambar 5. Pada gambar tersebut dapat terlihat bahwa golongan metabolit skunder yang mempunyai aktivitas antimikroba merupakan senyawa dengan kisaran nilai Rf sebesar 0.11-0.64.

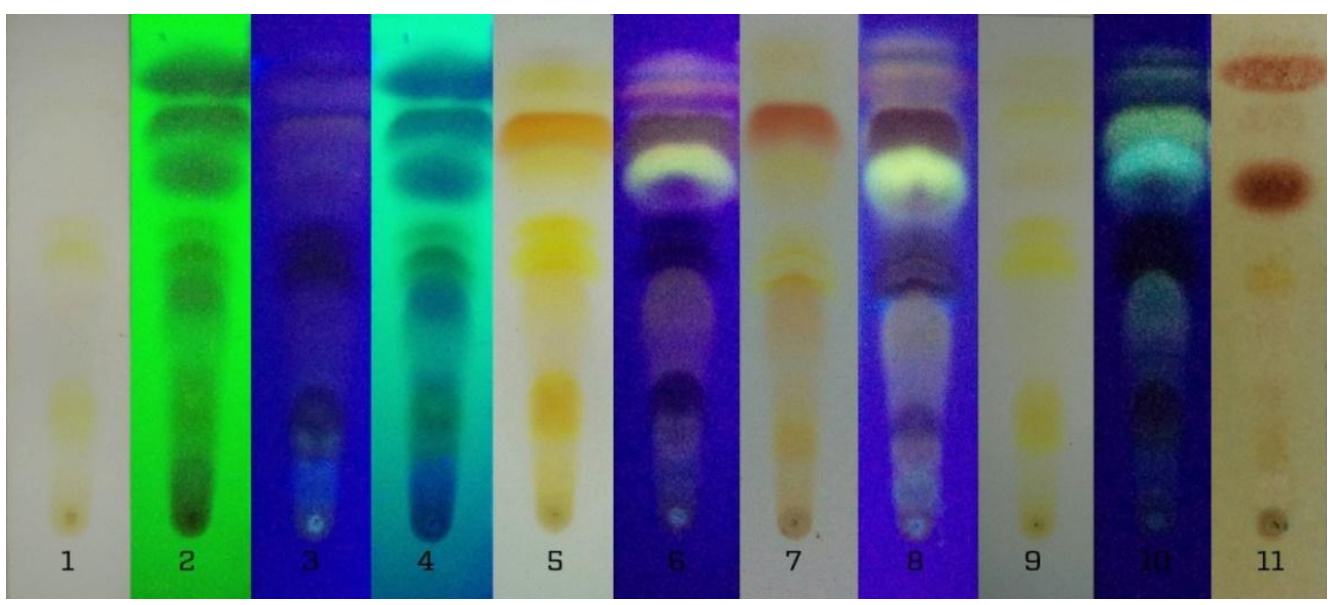

Gambar 5. Kromatogram B. pandurata, 1 (Visibel), 2 (UV-254 nm), 3 (366 nm), 4 (UV254+366 nm), $5\left(\mathrm{H}_{2} \mathrm{SO}_{4}\right), 6\left(\mathrm{H}_{2} \mathrm{SO}_{4}+\mathrm{UV} 366\right), 7$ (LB), 8 (LB+UV366), 9 (Sitroborat), 10 (Sitroborat+UV366), $11\left(\mathrm{FeCl}_{3}\right)$ Pengembang n-heksan : etil asetat $(7: 3)$. 
Berdasarkan hasil identifikasi golongan metabolit skunder, diketahui bahwa senyawa pada spot dengan nilai Rf $0.18,0.26,0.49$, dan 0.53 diduga merupakan flavonoid dengan hasil positif berwarna kuning terang setelah disemprot menggunakan $\mathrm{H}_{2} \mathrm{SO}_{4} 10 \%$. Sementara itu, spot yang terbentuk setelah ditambahkan pereaksi sitroborat dengan nilai $\mathrm{Rf}$ 0,61 dan 0,64 diduga merupakan flavonoid dengan hasil positif berwarna kuning terang dan kuning kehijauan (dilihat mengunakan lampu UV $366 \mathrm{~nm}$ ). Adapun mekanisme kerja golongan senyawa flavonoid sebagai antimikroba atau antijamur adalah merusak membran sel jamur, sehingga sel jamur mengalami kerusakan, pertumbuhannya terhambat, dan pada akhirnya akan mati (Warsinah, dkk., 2011).

\section{Kesimpulan}

Ekstrak etanol rimpang $B$. pandurata (temu kunci) mempunyai aktivitas terhadap jamur penyebab Pitiriasis versikolor (Malassezia sp. Malassezia globosa dan Malassezia furfur) dengan KHM $3 \%$ dan KBM $10 \%$. Golongan senyawa metabolit sekunder yang memberikan aktivitas antimikroba adalah golongan flavonoid.

\section{DAFTAR PUSTAKA}

BPOM RI. 2007. Acuan Sediaan Herbal, ed. 1. Jakarta: Badan Pengawas Obat dan Makanan Republik Indonesia.

BPOM RI. 2011. Acuan Sediaan Herbal, ed 1. Jakarta: Badan Pengawas Obat dan Makanan Republik Indonesia.

Budimulja U. 2007. Pitiriasis Versikolor, dalam Djuanda A, Hamzah M, Aisah S, eds. Ilmu penyakit kulit dan kelamin, ed. 5. Jakarta: Balai Penerbit FKUI.

Efendi, Yuli Nurullaili dan Hertiani, Triana. 2013. Antimicrobial Potency Of Ant-Plant Extract (Myrmecodia tuberosa Jack.) Against Candida albicans, Escherichia coli, and Staphylococcus aureus. Traditional Medicine Journal, Vol. 18, No. 1:53-58.

Eisai. 1995. PT. Medicinal herb index in Indonesia, $2^{\text {nd }}$ ed. Jakarta : PT. Eisai Indonesia.

Heyne, K. 1987. Tumbuhan berguna Indonesia I. Jakarta : Yayasan Sarana Wana Jaya.

Kirana, C, Jones, GP, Record, IR, McIntosh, GH.. 2007. Anticancer properties of panduratin A isolated from Boesenbergia pandurata (Zingiberaceae). Journal of Natural Medicines, Vol. 61:131-7.

Moniri, R., Nazeri, M., Amiri, S. \& Asghari, B.. 2009. Isolation and identification of Malassezia spp. in pytiriasis versicolor in Kashan, Iran. Pak J Med Sci, Vol. 25 : 837-40.

Pfaller, M., Diekema, D. \& Merz, W.. 2009. Infection caused by non Candida, non Cryptococcus yeasts. In Anaissie, E., Mcginnis, M. \& Pfaller, M. (Eds.) Clinical mycology. 2nd ed. Churchill Livingstone, Elsevier.

Rukayadi, Y, Lee, K, Han, S, Yong, D, Hwang, JK.. 2009. In vitro activities of panduratin A against clinical Staphylococcus strains. Antimicrobial agents and chemotherapy, Vol. 53 : 4529-32.

Rukayadi, Y, Han, S, Yong, D, Hwang, JK.. 2010. In vitro antibacterial activity of panduratin A against enterococci clinical isolates. Biol Pharm Bull, Vol. 33 : 148993.

Tewtrakul, S, Subhadhirasakul, S, Karalai, C, Ponglimanont, C, Cheenpracha, S.. 2009. Anti-inflammatory effects of compounds from Kaempferia parviflora and Boesenbergia pandurata. Food Chemistry, Vol. 115 : 534-8.

Tuchinda, P, Reutrakul V, Claeson P, Pongprayoon U, Sematong, T, Santisuk T, Taylor W C.. 2002. Anti-inflammatory cyclohexenyl chalcone derivatives in Boesenbergia pandurata. Phytochemistry, Vol. 59 : 169-73. 
Warsinah, Kusumawati, Eka, dan Sunarto. 2011. Identifikasi Senyawa Antifungi dari Kulit Batang Kecapi (Sandoricum koetjape) dan Aktivitasnya Terhadap Candida albicans. Majalah Obat Tradisional, Vol. 16, No. 3 : 165-173.

Win, NN, Awale, S, Esumi, H, Tezuka, Y, Kadota, S.. 2008. Panduratins D-I, novel secondary metabolites from rhizomes of Boesenbergia pandurata. Chemical \& pharmaceutical bulletin, Vol 56 : 491-6.

Yanti, Rukayadi, Y, Lee, KH, Hwang, JK.. 2009. Activity of panduratin A isolated from Kaempferia pandurata Roxb. against multi-species oral biofilms in vitro. Journal of Oral Sci, Vol. $51: 87-95$. 